\title{
Congenital transmission of Trichinella spiralis in experimentally infected mice
}

\author{
J. CUI*, Z. Q. WANG, H. M. HAN
}

\author{
Department of Parasitology, Medical College of Zhengzhou University, Zhengzhou 450052, P. R. China, \\ E-mail: cuij@zzu.edu.cn
}

\begin{abstract}
Summary
Congenital transmission of $T$. spiralis infection in BALB/c mice was studied. Pregnant mice were each infected with 300 larvae 5, 7, 15 and 17 days after fertilization. Newborn mice were examined by artificial digestion of muscles. Out of 6 offspring born to the mother-mouse infected 7 days after fertilization, two offspring were found to be infected, 7 and 24 larvae were recovered respectively. Other 7 female mice were first infected with $T$. spiralis larvae and then gestated, only the offspring born to the mother-mice fertilized 8 and 22 days after infection were found to be infected with a larval burden ranging from $1-3$ larvae per animal. All of the larvae recovered from the offspring were the non-encapsulated larvae. The cross-fostering in which one-day old young born to healthy mother-mice were nursed by infected mothers for 21 days, showed that no young were found to be infected. These findings showed that tansplacental transimission of $T$. spiralis could occur in mice, if the female were infected during mid-pregnancy or fertilized in 1 month after infection (e.g., infected in one month before fertilization). The larvae transmitted from maternal-to-neonatal mice may be migrating. Transmammary transimission of $T$. spiralis was not observed.
\end{abstract}

Key words: Trichinella spiralis; congenital; transmission; mice

\section{Introduction}

Trichinellosis is a serious parasitic zoonosis widely distributed in the world. Human beings acquire the disease mainly by ingesting raw or insufficiently cooked pork and pork products containing Trichinella larvae. Out of 548 outbreaks of trichinellosis which occurred in China during 1964 - 1999, 525 were resulted from the ingestion of pork (Wang \& Cui, 2001a). The prevalence of Trichinella infection in swine was correlated to the prevalence of Trichi- nella infection in rat in China (Wang \& Cui, 2001b). Although the role played by rats in the transmission of trichinellosis to pigs has been a topic of debate for more than 100 years and definitive conclusions have yet to be reached (Murrell et al., 1987; Pozio, 2000). However, it has been shown that transmission in a swine herd can be stopped, if a microbiological barrier is introduced against rodents and other synanthropic animals in the pigsties and in the foodsilos together with other control measures (Pozio, 1998). In addition, mice have a potential role in the transmission of Trichinella infection in horse that possibly acquires the infection by grazing in pastures contaminated with the infected rodent carcasses (Pozio, 2001).

Transplacental penetration of Trichinella larvae has been recorded in few animals such as pigs, guinea-pigs, rats and rabbits (Hartmanova \& Chroust, 1968; Cosoroaba \& Orjanu, 1998). However, only pigs and rats are of epidemiological importance, since guinea-pigs and rabbits have no role in the transmission of trichinellosis. Additionally, the transplacental transmission of trichinellosis in humans is also possible. A pregnant woman was infected with Trichinella britovi larvae in the 10th week of pregnancy during an outbreak of trichinellosis in the Slovak Republic. Abortion was performed in the 22nd week of pregnancy and the placenta, body cavities liquid, tissues and organs of the foetus all contained Trichinella larvae (Dubinský et al., 2001). Since the importance of this alternative route of transmission is obvious not only in animals but also in humans, further investigation is needed. The mouse placenta exhibits anatomical feature resembling the placenta anatomy in humans (Bjorkman et al., 1989), therefore, our study has been conducted on mice.

The purpose of the present study was to confirm further the transplacental or transmammary (lactogenic) transmission of $T$. spiralis infection in mice. Furthermore, the transmission of $T$. spiralis to offspring from mother mice infected

\footnotetext{
* Corresponding author
} 
in the middle of the gestation was compared with the transmission when infections were given to mother mice during early or late gestation.

\section{Materials and Methods}

\section{Parasite}

The $T$. spiralis used in this study had a swine source from Henan, province of China, and maintained by serial passage in Sprague-Dawley (SD) rats every 6-8 months. Each rat was orally infected with about $500 \mathrm{~T}$. spiralis larvae.

\section{Animals}

Forty-days-old specific pathogen-free BALB/c mice were used in this work. The mice were obtained from the Experimental Animal Center of Tongji Medical College, Huazhong University of Science and Technology (Wuhan, China) and were bred in plastic micro-isolator cages. The animals were divided into three groups.

Group 1 (mice infected with $T$. spiralis after fertilization): 10 males and 10 females, all of them forty-days-old, were used. One male and one female were bred in each cage. Pregnant mice were orally infected with $300 \mathrm{~T}$. spiralis muscle larvae (see digestion method) per animal 5, 7, 15, 17 days after fertilization. The offspring born to infected dams were examined by the artificial digestion method. The dams were also examined by the same method one day after delivery for specifying the degree of infection.

Group 2 (mice infected with $T$. spiralis before fertilization): 3 males and 18 females, all of them forty-days-old, were used. The females were orally infected with $300 \mathrm{~T}$. spiralis muscle larvae per animal. The mice were randomly divided into 3 cages (one male and six females per cage) in one day after infection. The newborn mice and their dam were examined by the above-mentioned methods for larva burdens in one day after birth.

Group 3 (mice cross-fostered after birth): 30 one-day-old offspring born to healthy mother mice were nursed by three infected dams, which were orally infected with 300 $T$. spiralis muscle larvae per animal 3, 7, 11 days after fertilization, respectively. The young were examined by the method previously mentioned on day 21 after birth.

\section{Identification of gestation of female mice}

The females were examined for vaginal plug every morning. Then, slides with vaginal secretion were examined under light microscope for sperms. The presence of vaginal plug and sperms was taken as day 1 of pregnancy. The moment of fertilization was further confirmed according to the date of birth to find out the gestation stage, when larvae first started migrating.

\section{Digestion method and muscle larval burden}

Muscle larvae were recovered from the carcasses of infected animals killed with ether after 30 days post infection by the digestion method using $1 \%$ pepsin- $1.5 \% \mathrm{HCl}$ (Cui et al., 1999). The proteolytic power of the pepsin used was of 1:3 000; the artificial gastric juice was prepared on the day of the examination. The collected muscle larvae were washed and suspensions suitably diluted in normal saline solution. Larvae were then counted twice by two independent observers using a light microscope. Calculations were then performed to express larval burden as the number of larvae per gram of carcass digested. For the determination of the parasite burdens in the offspring the same methodology was employed and the results expressed the number of larvae per animal.

\section{Results}

The gestation period of mice lasted normally from 19 to 21 days. In group 1, 4 out of 10 female mice were gestated during the experiment. Out of 6 offspring born to the mother-mouse infected 7 days after fertilization, two offspring were found to be infected, 7 and 24 larvae were recovered respectively (Table 1). All mother mice of group 1 had also been infected. In group 2, out of 18 female mice infected with $T$. spiralis larvae, 7 female mice were gestated on days $8-60$ days after infection, the remaining 11 females were not gestated. Only the offspring born to the mothermice fertilized at 8 and 22 days after infection were found to be infected, the infection rate of offspring was $20 \%$ $(2 / 10)$ and $25 \%(2 / 8)$ respectively, with a larval burdens ranging from $1-3$ larvae per animal (Table 2.). All the larvae recovered from the offspring were the non-encapsulated larvae.

In group 3, the results of cross-fostering experiment showed that all the young mice born to healthy mother-mice, and nursed by infected mothers for 21 days, were not found to be infected. It suggests that the infection of the offspring should not be attributed to lactogenic transmision.

Table 1. Parasitological studies on offspring born to dams infected with $T$. spiralis after fertilization (Group 1)

\begin{tabular}{|c|c|c|c|c|c|}
\hline $\begin{array}{l}\text { Mother } \\
\text { mice }\end{array}$ & $\begin{array}{l}\text { Infecting: days after } \\
\text { fertilization }\end{array}$ & $\begin{array}{c}\text { No. } \\
\text { young born }\end{array}$ & $\begin{array}{c}\text { No. } \\
\text { young infected }\end{array}$ & $\begin{array}{l}\text { No. larvae recovered } \\
\text { from young }\end{array}$ & $\begin{array}{c}\text { Dam's larvae/gram } \\
\text { muscle }\end{array}$ \\
\hline 1 & 5 & 13 & - & - & 2225 \\
\hline 2 & 7 & 6 & 2 & $31 *$ & 1310 \\
\hline 3 & 15 & 11 & - & - & 1756 \\
\hline 4 & 17 & 10 & - & - & 2360 \\
\hline
\end{tabular}

*7 and 24 larvae were recovered from the young respectively 
Table 2. Parasitological studies on offspring born to dams infected with $T$. spiralis before fertilization (Group 2)

\begin{tabular}{|c|c|c|c|c|c|}
\hline $\begin{array}{c}\text { Female } \\
\text { mouse }\end{array}$ & $\begin{array}{l}\text { Fertilizating: days } \\
\text { after infection }\end{array}$ & $\begin{array}{c}\text { No. } \\
\text { young born }\end{array}$ & $\begin{array}{c}\text { No. } \\
\text { young infected }\end{array}$ & $\begin{array}{l}\text { No. larvae recovered } \\
\text { from young }\end{array}$ & $\begin{array}{c}\text { Dam's larvae/gram } \\
\text { muscle }\end{array}$ \\
\hline 1 & 8 & 10 & 2 & $5 *$ & 809 \\
\hline 2 & 18 & 9 & - & - & 1889 \\
\hline 3 & 22 & 8 & 2 & 2 & 1721 \\
\hline 4 & 27 & 17 & - & - & 1429 \\
\hline 5 & 44 & 18 & - & - & 1241 \\
\hline 6 & 50 & 12 & - & - & 1078 \\
\hline 7 & 60 & 11 & - & - & 1339 \\
\hline
\end{tabular}

*3 and 2 larvae were recovered from the offspring respectively

\section{Discussion}

It is known that female adults of $T$. spiralis begin to shed newborn larvae from the 5th day after infection, which continues for as long as the female worms remain in the inestine. The birthing continues for the next 4 to 16 weeks. Maximum numbers of newborn larvae were produced in mice on day 7 of the infection. The total newborn larva production per female (in rodents) varies from 200 to 1660 larvae (Harley \& Gallicchico, 1971; Despommier, 1983). On being deposited in the mucosa, most of the newborn larvae migrate into the lamina propria and then either into the mesenteric lymphatics or directly into the bloodstream. All larvae eventually enter the general circulation and are distributed throughout the body.

In the present study, two of six offspring born to the dam infected with $T$. spiralis 7 days after fertilization were found to be infected, but the other offspring born to the dams infected during early-or late-gestation $(5,15,17$ days after fertilization) were not infected. The results demonstrated that only a few larvae crossed the placenta. Although the exact timing is unknown, it seems that the second week (mid-gestation) is the most favorable moment for the occurrence of transplacental infection. In group 2, 7 female mice infected with $T$. spiralis larvae were fertilized from $8-60$ days after infection. Only the offspring born to the mother-mice fertilized 8 and 22 days after infection were found to be infected, suggesting that congenital infection occurred mainly in one month after infection with T. spiralis.

The newborn larvae migrate throughout the body, via the blood and lymph circulatory system. Although the newborn larvae may invade many different tissues, they are only encapsulated in striated skeletal muscle cells. In this study, all the larvae recovered from the offspring were the non-encapsulated larvae. Since it is not sure whether the larvae passing into the fetus derive from the larvae produced in the first days of the females' lives or during their last days, it is difficult to specify the age of the larvae that reach the muscles of the offspring born to the infected dams. Therefore, it is not clear whether the larvae in the muscles of the offspring could be encapsulated.

The cross-fostering, during which one-day old young mice born to healthy mother-mice were nursed by infected mothers for 21 days, showed that no young were infected. $T$. spiralis larvae behave differently from other nematodes such as those of Toxocara canis, Ancylostoma caninum Strongyloides stercoralis which produced in the hosts can pass through the mammary tissues (Tomašovičová et al., 1993; Arasu \& Kwak, 1999; Shoop et al., 2002). Once $T$. spiralis larvae settled down in the skeletal muscles they never leave the muscles. These data suggested that the Trichinella infection of the offspring should not be attributed to lactogenic transmission.

Our results were similar to the work of Cosoroaba and Orjanu (1998) in which they documented that the migrant larvae of $T$. spiralis cross the placental barrier and thus infect the conceptus in rats, but the larvae inoculation used for infection in their work was a 70-fold higher than the one applied here. An abortion of one pregnant woman with trichinellosis was also reported during an outbreak in China (Zhang \& Pang, 1999). This study is of importance in endemic areas where outbreaks of trichinellosis involving pregnant women can occur (Cui et al., 1997). In addition, the side-effects of albendazole or mebendazole treatments in mothers and their offspring should be further investigated.

To conclude, the tansplacental transimission of $T$. spiralis may occur in mice if female mice are infected during midpregnancy or fertilized in one month after infection (e.g., infected in one month before fertilization). The larvae transmitted from maternal-to-neonatal mice may be migrating ones. The transmammary transimission of $T$. spiralis was not observed.

\section{Acknowledgement}

This study was supported by the Natural Science Grant of Henan Province, R.P. China.

\section{References}

ARASU, P., KWAK, D. (1999): Developmental arrest and pregnancy-induced transmammary transmission of Ancy- 
lostoma caninum larvae in the murine model. J. Parasitol., 85: $779-784$

BJorkman, N., DANTZER, V., LeISER, R. (1989): Comparative placenta in laboratory animals. Scand. J. Lab. Anim. Sci., 16: $129-158$

Cosoroaba, I., OrJanu, N. (1998): Congenital trichinellosis in the rat. Vet. Parasitol., 77: $147-151$

CUI, J., WANG, Z. Q., WU, F., JIN, X. X. (1997): Epidemiological and clinical studies on an outbreak of trichinosis in central China. Ann. Trop. Med. Parasitol., 91: 482 - 488

CuI, J., WANG, Z. Q., Jin, X. X., ZHU, W., Wu, F. (1999): Seroepidemiologicl study of Trichinella spiralis infection in central China. Helminthologia, 36: 235 - 239

Despommier D. D. (1983): In CAMPBell, W. C. (Ed): Trichinella and trichinosis. Plenum Press and London. Bio$\log y, 75-151$

DuBINSKÝ, P., BOOR, A., KINČEKOVÁ, J., TOMAŠOVIČOVÁ, O., ReiterovÁ, K., BieliK, P. (2001) Congenital trichinellosis? Case report. Parasite, 8: $180-182$

Harley, J. P, Gallicchico, V. (1971): Trichinella spiralis: migration of larvae in the rats. Exp. Parasitol., 30: 11 12

Hartmanova, B., Chroust, R. (1968): Congenital trichinellosis. Acta Univ. Agric. Brno, 37: 93 - 103

Murrell, K. D., Stringfellow, F., Dame, J. B., Leiby, D. A., DufFy, C., ScHAD, G. A. (1987): Trichinella spiralis in an agricultural ecosystem. II. Evidence for natural trans- mission of Trichinella spiralis spiralis from domestic swine to wildlife. J. Parasitol., 73: 103 - 109

PozIO, E. (1998): Trichinellosis in the European Union: epidemiology, ecology and economic impact. Parasitol. Today, 14: 35 - 38

POZIO, E. (2000): The domestic, synanthropic and sylvatic cycles of Trichinella and the flow among them. Vet. Parasitol., 93: $241-262$

PozIO, E. (2001): New patterns of Trichinella infection. Vet. Parasitol., 98: $133-148$

Shoop, W. L., Michael, B. F., EARY, C. H., Haines, H. W. (2002): Transmammary transmission of Strongyloides stercoralis in dogs. J. Parasitol., 88: 536 - 539

TOMAŠOVICOVÁ, O., HavasiovÁ-ReiterovÁ, K., DubiNSKÝ, P., HOVORKA, I. (1993): Intrauterine and lactogenic transfer of Toxocara canis larvae in paratenic hosts. Helminthologia, 30: 111-113

WANG, Z. Q., CUI, J. (2001a): Epidemiology of human trichinellosis in China during 1964 - 1999. Parasite, 8: 63 66

WANG, Z. Q., CUI, J. (2001b): Epidemiology of swine trichinellosis in China. Parasite, 8: $67-70$

ZhANG, H. M., PANG, Y. K. (1999): Epidemiological investigation on an outbreak of human trichinellosis in Jingping county of Yunnan province of China. Med. Pest Control, 15: $30-31$

ACCEPTED FEBRUARY 17, 2006 